\title{
Effects of Encainide and Amiodarone on the Adaptation of Ventricular Refractoriness to an Increase in Rate
}

\author{
Shimon Rosenheck, MD, Stephen Schmaltz, MPH, Alan H. Kadish, ivD, and Fred Morady, MD
}

$\mathbf{T}$ he ventricular effective refractory period (VERP) adapts gradually to an increase in rate, and up to several minutes may be necessary before the maximum shortening of VERP is realized when the rate increases. ${ }^{1,2}$ Quinidine and mexiletine have been demonstrated to have no effect on the adaptation of ventricular refractoriness to an increase in rate. ${ }^{3}$ However, the effects of class IC and class III antiarrhythmic drugs on the adaptation of refractoriness to an increase in rate are not known. Therefore, the purpose of this study was to evaluate the effects of encainide and amiodarone on the adaptation of the VERP to an increase in rate.

Seventeen subjects were selected from among a pool of patients undergoing a clinically indicated electrophysiology test. These patients had inducible sustained ventricular tachycardia (VT) that was not adequately controlled by a class IA or IB antiarrhythmic drug. Patients in whom VT was inducible with 1 extrastimulus or in whom continuous ventricular pacing at a cycle length of $500 \mathrm{~ms}$ was not hemodynamically tolerated were exclud. ed from the study. In addition, patients who had a left ventricular ejection fraction of $<30 \%$ were not treated with encainide. The mean age of the subjects ( 16 men, I woman) was $61 \pm 9$ years (mean \pm standard deviation). Sixteen patients had coronary artery disease and 1 patient had no structural heart disease. The mean left ventricular ejection fraction was $0.33 \pm 0.15$.

Electrophysiology studies were performed with patients in the fasting, unsedated state after informed consent was obtained. Each patient had a baseline study performed at least 5 half-lives after all antiarrhythmic treatment was discontinued. A quadripolar electrode catheter was positioned in the right ventricular apex. Bipolar pacing was performed with a programmable stimulator (Bloom Associates Ltd.) at a current strength twice threshold and a pulse width of $2 \mathrm{~ms}$. VERPs were measured using drive trains of 2,8 and 20 beats at a cycle length of $500 \mathrm{~ms}$ and a 3-second intertrain pause. An extrastimulus $\left(S_{3}\right)$ was delivered at a coupling interval shorter than the expected refractory period and the coupling interval was increased in 2-ms steps until ventricular capture was obtained. This incremental method of measuring the VERP was used because it yields a more accurate estimate of the VERP than a decremental method." To measure the "steady-state" VERP, 3 minutes of continuous ventricular pacing were performed at a cycle length of $500 \mathrm{~ms}$; then an $S_{2}$ was inserted after every 8 beats, without a pause. We used 3 minutes of

From the Division of Cardiology, B1F245, and the Clinical Research Center, Department of Internal Medicine, University of Michigan Medical Center, Ann Arbor, Michigan 48109-0022. This study was supported in part by grant 5M01-RR00042-25 from the National Institutes of Health. Bethesda, Maryland. Manuscript received January 8. 1990; revised manuscript received and accepted March 1, 1990.
TABLE I The Effect of Drive Train Duration and Encainide on the Ventricular Effective Refractory Period (in ms) in Seven Patients

\begin{tabular}{|c|c|c|c|c|}
\hline & \multicolumn{4}{|c|}{ Drive Train Duration } \\
\hline & 2 beats & 8 beats & 20 beats & 3 minutes \\
\hline Baseline & $257 \pm 22$ & $251 \pm 18$ & $244 \pm 16$ & $231 \pm 7$ \\
\hline Encainide & $288 \pm 26^{*}$ & $275 \pm 25 *$ & $267 \pm 24^{*}$ & $248 \pm 19 \%$ \\
\hline IVERP' & $31 \pm 14$ & $24 \pm 15$ & $23 \pm 16$ & $17 \pm 17$ \\
\hline
\end{tabular}

TABLE II The Effect of Drive Train Duration and Amiodarone on the Ventricular Effective Refractory Period (in $\mathrm{ms}$ ) in Ten Patients

\begin{tabular}{|c|c|c|c|c|}
\hline & \multicolumn{4}{|c|}{ Drive Train Duration } \\
\hline & 2 beats & 8 beats & 20 beats & 3 minutes \\
\hline Baseline & $265 \pm 16$ & $256 \pm 16$ & $247 \pm 14$ & $237 \pm 11$ \\
\hline Amiodarone & $302 \pm 19^{*}$ & $295 \pm 19^{*}$ & $287 \pm 21 *$ & $272 \pm 18^{*}$ \\
\hline
\end{tabular}

pacing because this was previously found adequate to obtain maximal shortening of the VERP after an increase in rate.' The $S_{2}$ coupling interval was again increased in steps of $2 \mathrm{~ms}$ until ventricular capture was obtained. The VERP was defined as the longest coupling interval that did not result in ventricular capture.

Seven patients received $118 \pm 21 \mathrm{mg} /$ day of encainide for 4 to 5 days and then underwent a repeat electrophysiology study. The mean plasma encainide, O-demethyl encainide $(O D E)$ and 3-methoxy-O-demethyl encainide $(M O D E)$ concentrations at the time of the electrophysiology study were $34 \pm 43,108 \pm 104$ and $49 \pm 31 \mathrm{ng} / \mathrm{ml}$, respectively. Ten patients were treated with $2.4 \mathrm{~g} /$ day of amiodarone and then underwent a repeat electrophysiology study after 2 weeks of treatment. The mean plasma amiodarone and desethyl amiodarone concentrations were $2.8 \pm 0.8$ and $1.4 \pm 0.3 \mathrm{mg} / \mathrm{ml}$, respectively, at the time of the repeat electrophysiology study. The stimulation protocol was identical in the baseline state and after treatment with encainide or amiodarone. To analyze the drug effect, the effect of the drive train duration and the interaction between them, a repeated measures analysis of variance was used. ${ }^{5}$ Multiple comparisons were evaluated using Fisher's least significant difference procedure. ${ }^{6}$ A p value $<0.05$ was considered significant.

Encainide did not significantly affect the sinus cycle length. In the baseline state, the VERP shortened progressively as the drive train duration increased ( $p$ $<0.0001)$. Encainide significantly prolonged the VERP at all drive train durations ( $p<0.01$, Table I). However, its effect on the VERP became less pronounced as the 


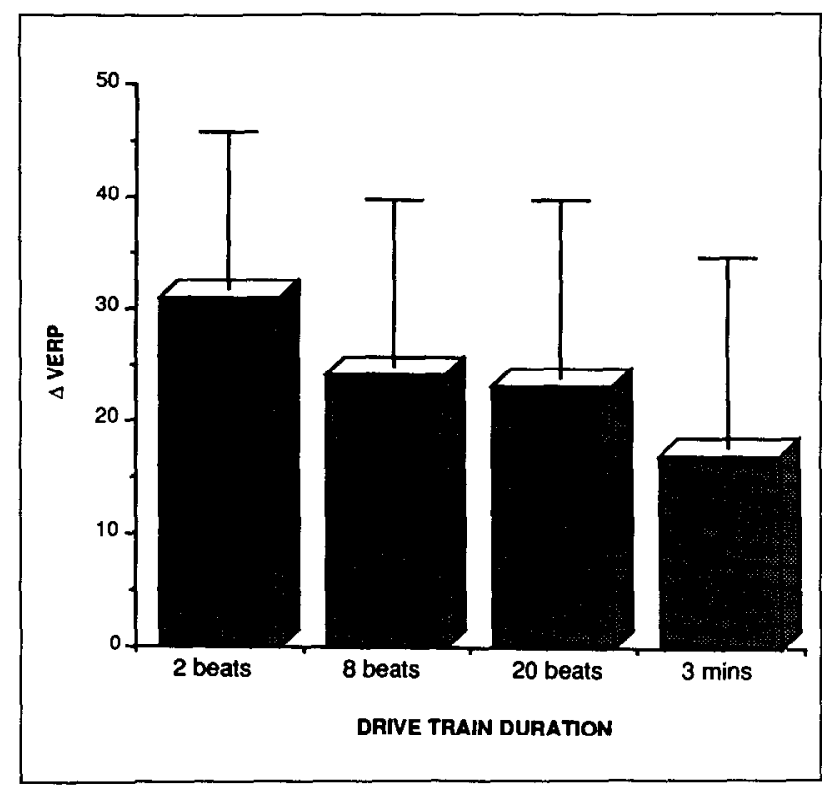

FIGURE 1. The change in the ventricular effective refractory period ( $\triangle$ VERP) caused by encainide in 7 patients. Encainide prolonged the VERP by a mean of $31 \mathrm{~ms}$ when the drive train duration was 2 beats compared to 17 ms when the drive train duration was 3 minutes $(p<0.001)$. There was a significant trend for $\triangle$ VERP to decrease as the drive train duration increased $(p<0.05)$.

duration of the basic drive train increased $(p<0.05$, Figure 1). The plasma encainide and ODE concentration correlated significantly with the prolongation of the $V E R P$ only at a basic drive train duration of 3 minutes $(p<0.05)$.

Amiodarone did not significantly affect the sinus cycle length. In the baseline state, the VERP progressively shortened as the drive train duration increased ( $p$ $<0.001)$. Amiodarone significantly prolonged the VERP at all drive train durations ( $p<0.001$, Table II) and its effect on the VERP was similar at all basic drive train durations.

The results of this study demonstrate that encainide, a class IC antiarrhythmic drug, prolongs the VERP at all drive train durations. However, the effects of encainide become less pronounced as the drive train duration increases from 2 beats to 3 minutes. In contrast to encainide, amiodarone prolongs the VERP to the same degree at all drive train durations, and no interaction between the basic drive train duration and the effect of amiodarone on the VERP could be demonstrated. Conventional measurements of VERP have used a basic drive train duration of 8 beats, and previous studies have demonstrated that the actual "steady-state" VERP may be up to $40 \mathrm{~ms}$ shorter than the conventional VERP. ${ }^{1}$ The results of the present study demonstrate that amiodarone's effect on the steady-state VERP is accurately reflected by its effect on the conventionally measured VERP. However, encainide's effect on the conventional VERP overestimates its effect on the steady-state VERP. The mechanism by which encainide alters the adaptation of VERP to an increase in rate remains to be determined.

1. Morady F, Kadish AH, Toivonen LK, Kushner JA, Schmaltz S. The maximum effect of an increase in rate on human ventricular refractoriness. PACE 1988:11:2223-2234

2. Boyett MR, Jewell BR. Analysis of the effect of changes in rate and rhythm upon electrical activity in the heart. Prog Biophysiol Mol Biol 1980;36.1-52. 3. Rosenheck S, Schmaltz S, Kadish AH, Summitt J, Morady F. The effect of quinidine and mexiletine on the adaptation of ventricular refractoriness to an increase in rate (submitted for publication).

4. Morady F, Kadish AH, Kushner JA, Toivonen LK, Schmaltz S. Comparison of ventricular refractory periods determined by incremental and decremental scanning of an extrastimulus. PACE 1989;12:546-554.

5. Berk K. Computing for incomplete repeted measures. Biometrics 1987;43:385 398.

6. Milliken JA, Johnson DE. Analysis of Messy Data. Volume I: Designed Experiments. New York: Van Nostrand Reinhold, 1984:322-350.

\title{
Utility of Transesophageal Echocardiography in Interatrial Septal Puncture During Percutaneous Mitral Balloon Commissurotomy
}

\author{
Raj S. Ballal, MD, Edward F. Mahan II, MD, Navin C. Nanda, MD, and Larry S. Dean, MD
}

$\mathbf{P}$ ercutaneous mitral balloon commissurotomy is an alternative to surgical therapy in selected patients with symptomatic mitral stenosis. ${ }^{1}$ Transseptal cardiac catheterization is the most common approach and complications are rare with experienced personnel but include perforation of the aorta, atria and left ventricular wall. ${ }^{2}$ Transthoracic 2-dimensional echocardiography has also been used to guide balloon valvuloplasty catheters as well as the transseptal needle across the atrial septum ${ }^{3}$ but may be limited by an inadequate acoustic window, transducer and catheter images superimposed in the fluoroscopic field and suboptimal atrial septum and fossa ovalis

From the Division of Cardiovascular Disease, Department of Medicine, University of Alabama at Birmingham, Heart Station, SWB/W102, Birmingham, Alabama 35294. Manuscript received January 22, 1990; revised manuscript received and accepted March 8, 1990. visualization. In contrast, transesophageal echocardiography (TEE) encounters minimal acoustic impedance due to lung or skeletal tissue and yields very high quality images. ${ }^{4}$ Using TEE, successful visualization of the atrial septum and the membranous portion of fossa ovalis is practically always achieved. The purpose of the current study is to evaluate the usefulness of TEE as an aid to transseptal cardiac catheterization during balloon commissurotomy.

Four female patients with mitral stenosis and New York Heart Association class III or IV congestive heart failure were studied. The patients ranged in age from 20 to 68 years (mean 42). After right-and left-sided cardiac catheterization, the patients were turned to the left side and the transesophageal probe was introduced in the esophagus and positioned posterior to the left atrium, after giving 1 to $2 \mathrm{mg}$ of medazolane intravenously and 